\title{
Influência do risco de litígio do auditor nos honorários de auditoria e de não auditoria
}

\author{
Mikaéli da Silva Giordani \\ https://orcid.org/0000-0002-4871-7858 | E-mail:mikagiordani@hotmail.com \\ Justine Maria Arruda de Souza Neto \\ https://orcid.org/0000-0001-7892-4738 | E-mail: justine.contabilidade@gmail.com \\ Paulo Roberto da Cunha \\ https://orcid.org/0000-0001-5805-9329 | E-mail: pauloccsa@furb.br
}

\section{Resumo}

Objetivo: Analisar a influência do risco de litígio do auditor nos honorários de auditoria e de não auditoria. Método: Realizou-se pesquisa descritiva, documental e com abordagem quantitativa. A população compreendeu empresas listadas nos Estados Unidos da América e a amostra correspondeu a 1.298 empresas para cada ano de análise, que abrangeu o período de 2013 a 2017. Os dados foram coletados na base de dados da Thomson Reuters Eikon ${ }^{\circledR}$ e analisados por meio da estatística descritiva, correlação e de regressão.

Resultados: Verificou-se que o risco de litígio e variáveis de controle influenciam nos honorários de auditoria. Isso indica que, diante de um alto risco de litígio, os auditores são inclinados a despender mais esforço e tempo na aplicação de testes e, consequentemente, a cobrar honorários maiores. Da mesma forma, observou-se a influência do risco de litígio nos honorários de não auditoria. Perante um alto risco de litígio, os auditores são motivados a realizar um trabalho especializado, que resulta em maiores valores cobrados.

Contribuições: Este estudo contribui ao fornecer evidências empíricas sobre o reflexo econômico do risco de litígio do auditor, mensurado por meio de características do cliente, nos honorários de auditoria e de não auditoria, sendo de $18 \%$ e $1,3 \%$, respectivamente.

Palavras-chave: Risco de Litígio; Honorários de Auditoria; Honorários de Não Auditoria. 


\section{Introdução}

A auditoria tem como propósito assegurar a fidelidade dos registros e proporcionar a credibilidade das informações contábeis. Diante da crescente complexidade das transações comerciais e dos padrões contábeis, a auditoria aumenta o potencial de agregar valor ao cliente (DeFond \& Zang, 2014). Sendo que, em um mercado competitivo, observa-se o aumento das exigências dos usuários externos, principalmente bancos e instituições financeiras, por auditorias mais abrangentes (Jaramillo, Benau \& Grima, 2012). Esses fatos, tornam importante que o auditor avalie características da empresa auditada, como o uso de tecnologias e a complexidade do negócio, a fim de estar ciente dos riscos envolvidos no ltrabalho.

Nesse sentido, o risco de litígio tornou-se uma preocupação constante para os auditores (Sun \& Liu, 2011), pois é responsabilidade destes, com base nas evidências e nos julgamentos, emitir uma opinião sobre as demonstrações contábeis. Nesse processo, inevitavelmente os auditores incorrem em diferentes tipos de riscos, como os de reputação e de litígio. O risco de litígio expõe os auditores a sanções financeiras, enquanto o risco de reputação prejudica a capacidade de retenção e atração de novos clientes. Enquanto o risco de litígio cria um passivo, o risco de reputação afeta o ativo, a reputação do auditor. Destaca-se que tais riscos não são independentes, pois litígios e sanções financeiras podem prejudicar a reputação do auditor (DeFond \& Zang, 2014).

O risco de litígio representa uma ameaça aos auditores, sendo necessário avaliar continuamente a exposição ao risco, o planejamento do trabalho prestado e o custo dos serviços. Nesse sentido, tratando-se dos custos, os honorários de auditoria modificam-se de acordo com o risco de litígio presente (Seetharaman, Gul \& Lynn, 2002). Os honorários de auditoria abrangem os valores cobrados pelos auditores de seus clientes que correspondem aos serviços prestados pela revisão das demonstrações financeiras. Além disso, os auditores também fornecem serviços de não auditoria, conforme a necessidade do cliente, que envolvem atividades como: duediligence, auditoria especial, verificação fiscal, fusões e aquisições, entre outros (Hoitash, Markelevich \& Barragato,2007).

Diferentes pesquisas apontam para os determinantes dos honorários de auditoria (Jaramillo, Benau \& Grima, 2012; Hoitash, Markelevich \& Barragato, 2007; Mayoral \& Segura, 2007; Joshi \& Bastaki, 2000). Hay, Knechel \& Wong (2006) destacam que os honorários de auditoria dependem do tamanho, da complexidade, do risco e de outras características do auditado, além dos atributos do auditor e das características do trabalho de auditoria. Dessa forma o valor cobrado pelo auditor referente aos honorários de auditoria, deve considerar os custos da realização do serviço, bem como as consequências do seu trabalho, como os riscos de reputação e de litígio (Mayoral \& Segura, 2007). Em síntese, o risco de litígio sinaliza que os auditores devem considerar os efeitos desses riscos na condução do trabalho, na emissão da opinião de auditoria e ao definir os honorários de auditoria e de não auditoria (Kaplan \& Willians, 2013).

No âmbito dos honorários de auditoria e de não auditoria, as pesquisas abordaram o tema em relação aos efeitos da responsabilidade social corporativa (Kim \& Park, 2013), a possível influência da qualidade da governança corporativa na remuneração do auditor (Zaman, Hudaib \& Haniffa, 2011), características do cliente na determinação dos honorários (Jaramillo, Benau \& Grima, 2012; Hay, Knechel \& Wong, 2006) e o relacionamento do cliente com o auditor (Whisenant, Sankaraguruswamy \& Raghunandan, 2003). Tratando-se do risco de litígio do auditor, pesquisas examinaram o risco de litígio do auditor referente ao mercado do cliente auditado, especificamente essas pesquisas se concentraram em empresas de capital aberto e fechado, ou em alguns setores do mercado, e assumem que esses fatores levam o auditor a uma exposição de risco de litígio maior (Badertscher, Jorgensen, Katz \& Kinney, 2014; Choi, Kim \& Liu, 2009; Venkataram, Weber \& Willenborg, 2008; Seethraman, Gul \& Lynn, 2002; Simunic \& Stein, 1996). 
No que tange ao risco de litígio do auditor, mensurado por meio de características do cliente, Sun \& Liu (2011) e Krishnan \& Zhang (2005) avançaram em relação ao tema, sobretudo, pautando-se no modelo desenvolvido por Shu (2000). Sun \& Liu (2011) avançaram com a literatura ao examinar o efeito do risco de litígio do auditor na qualidade da auditoria entre auditores Big Four e não Big Four e Krishnan \& Zhang (2005) evidenciam que a divulgação de relatórios de revisão pelas empresas auditadas diminui o risco de litígio do auditor. Deste modo, conforme destacado por Sun \& Liu (2011), a maioria dos estudos sobre riscos de litígio teve foco em nível de país, ao analisar o mercado no qual o cliente está inserido. Assim, observou-se possibilidade de pesquisas que abordem o risco de litígio do auditor, referente às características do cliente, em relação às firmas de auditoria.

Diante do exposto, o presente estudo pretende contribuir com a discussão de risco de litígio, porém com foco em observar os riscos inerentes do cliente, aplicando e testando o modelo de Shu (2000) e relacionando a ele os honorários de auditoria e de não auditoria. Dessa forma, busca-se responder a seguinte questão de pesquisa: Qual a influência do risco de litígio do auditor nos honorários de auditoria e de não auditoria? Assim, busca-se analisar a influência do risco de litígio do auditor nos honorários de auditoria e de não auditoria, das companhias abertas dos Estados Unidos da América.

Neste sentido, justifica-se estudar o risco de litígio do auditor por meio das características do cliente, pois este afeta mais explicitamente a responsabilidade legal do auditor do que o risco de litígio no nível do país (Sun \& Liu, 2011). Conforme DeFond \& Zhang (2014), a literatura sobre riscos de litígios do auditor em auditoria é predominantemente teórica. Esse fato sugere a realização de pesquisas empíricas sobre o tema que forneçam insights sobre o risco de litígio e auditoria (Abbott, Gunny \& Pollard, 2017), especificamente sobre o risco de litígio e os honorários de auditoria e honorários de não auditoria.

Justifica-se ainda que muitas pesquisas focaram nos antecedentes do risco de litígio do auditor (Schmidt, 2012; Cahan\& Zhang 2006; Heninger 2001; Lys \& Watts 1994). Diferentemente dessas pesquisas, este estudo propõe analisar possíveis consequentes do risco de litígio do auditor, especificamente, se o risco de litígio do auditor reflete no aumento dos honorários de auditoria e de não auditoria. O contexto analisado é justificado devido à mensuração do risco de litígio do auditor, desenvolvida por Shu (2000), referir-se ao ambiente norte-americano e este ser um mercado amplo que propícia um número de observações maior.

Uma contribuição importante deste estudo para a literatura é fornecer evidências sobre a relação entre o risco de litígio do auditor e os honorários de auditoria e de não auditoria. Ainda, o estudo contribui ao evidenciar fatores que determinam os honorários de auditoria, sendo este um assunto significativo para os órgãos reguladores nacionais e internacionais, que buscam identificar a base sobre a qual os honorários de auditoria devem ser determinados, os custos que devem ser cobertos e os fatores que devem ser considerados ao se estabelecer os honorários de auditoria (Kikhia, 2015).

Por fim, reitera-se que o estudo contribui ao buscar evidências sobre as consequências do risco de litígio decorrente do cliente e como os auditores reagem a esse risco. Essa pesquisa sugere que a ameaça de riscos de litígios sobre auditores direciona-os a uma resposta, a qual pode ser observada por meio dos honorários de auditoria e de não auditoria.

\section{Risco de Litígio e Honorários de Auditoria e de Não Auditoria}

A atividade de auditoria envolve características do cliente auditado, como aspectos de governança corporativa e financeiros, em que a inadequada gestão ou fraudes relacionadas ao cliente podem ocasionar processos judiciais que impactam a responsabilidade, o desempenho e as funções do trabalho do auditor (Sterzeck, 2017). Nesse contexto, o trabalho de auditoria envolve diferentes riscos para o auditor. O risco de litígio do auditor é definido como o risco de o auditor se envolver em um processo judicial, sendo que no presente estudo este risco tem como base características do cliente. $\mathrm{O}$ risco de auditoria é definido como o risco de o auditor expressar uma opinião de auditoria inadequada quando as demonstrações contábeis apresentam distorção relevante (Ghosh \& Tang, 2015). 
Assim, como parte do planejamento e da execução do trabalho de auditoria das demonstrações contábeis, os auditores são obrigados a fazer julgamentos relacionados ao risco do cliente. Esses julgamentos dos riscos permeiam o processo de auditoria como um todo, determinando decisões relativas à aceitação do cliente, a extensão dos testes de auditoria, a natureza das opiniões e os honorários de auditoria. Desta forma, o auditor desempenha um papel fundamental ao verificar a qualidade das demonstrações contábeis elaboradas pelo cliente (Simunic \& Stein, 1996).

Nesse sentido, a opinião do auditor comunica suas conclusões aos interessados na organização, e cabe ao auditor alertar os usuários das demonstrações contábeis sobre problemas iminentes nos relatórios financeiros ou controles internos da organização, que podem incluir problemas de continuidade operacional (Hope \& Langli, 2009) e riscos, como o de negócio da empresa auditada. Conforme Shu (2000), os auditores possuem informações sigilosas sobre seus clientes, em que uma renúncia do auditor pode sinalizar alto risco de litígio do auditor e afetar a empresa auditada de forma a causar a queda do preço das ações e um impacto negativo no crescimento organizacional.

A literatura aborda que os auditores podem tomar várias atitudes quando o seu risco de litígio é percebido como alto. Nesse contexto, os resultados dos estudos de Krishnan \& Krishnan (1997) e Shu (2000) fornecem evidências de que os auditores tendem a se desligar de compromissos que estão associados a alto risco de litígio. Conforme Krishnan \& Krishnan (1997), nas situações em que os auditores solicitam seu desligamento, há uma maior possibilidade de ocorrência de eventos litigiosos na empresa auditada do que quando os clientes dispensam seus auditores.

O risco de litígio do auditor está associado ao engajamento e, portanto, às características do cliente (Stice, 1991). Dessa forma, as preocupações do auditor sobre litígios estão relacionadas com as características do cliente auditado. A medida empírica desenvolvida por Shu (2000) tem a intenção de capturar o risco de litígio do auditor, para isso, a medida considera as características do cliente, pois, conforme Krishnan \& Zhang (2005), o risco de litígio do auditor está correlacionado ao risco de litígio do cliente.

Para determinar o risco de litígio do auditor, Shu (2000) com base em estudos sobre litígios, desenvolve um modelo para mensurar o risco de litígio do auditor por meio de características dos clientes. As variáveis que compõem o modelo de risco de litígio do auditor de Shu (2000) estão relacionadas a fatores que aumentam os incentivos dos clientes em processos judiciais. Tamanho, marketto book, proporção de ações negociadas, liquidez e dificuldade financeira durante o ano são características do cliente que podem aumentar o risco de litígio do auditor. No modelo, o retorno sobre os ativos apresentase positivamente relacionado ao risco de litígio do auditor, uma explicação é que altos retornos contábeis, juntamente com baixos retornos das ações, correspondem a indícios de gerenciamento de resultados, o que consequentemente pode levar a litígios contra auditores.

Para Stice (1991), o nível de contas a receber e estoque do cliente configuram-se na elevação do risco de litígio do auditor. Além disso, a opinião de auditoria modificada, a participação em um setor de alta tecnologia e o crescimento das vendas também aumentam a exposição legal do auditor.

Krishnan \& Krishnan (1997) afirmam que existem algumas maneiras em que os auditores conseguem controlar o risco de litígio, podendo se distanciar de obrigações de alto risco de litígio, sendo mais exigentes e cuidadosos na seleção de seus clientes e dando mais atenção e melhoria na qualidade da auditoria. Segundo os autores, a situação financeira do cliente está diretamente relacionada ao risco de litígio do auditor, sendo que os relatórios das demonstrações contábeis, bem como as opiniões dos auditores são maneiras de monitorar os contratos pelas partes.

Conforme Simunic \& Stein (1996), a qualidade da auditoria está associada ao risco de litígio e os autores argumentam que o aumento do risco do negócio do cliente pode levá-los a mudar sua demanda de auditores de alta qualidade para auditores de baixa qualidade. Segundo Shu (2000), o aumento dos riscos inerentes à empresa auditada reduz a qualidade de auditoria. A autora justifica que um alto risco de litígio do auditor, decorrente de características do cliente, leva à demissão do auditor, e que os auditores sucessores são não Big Four, o que sugere uma relação negativa entre o risco de litígio e a qualidade de auditoria. 
Segundo DeFond e Zhang (2014), os altos custos do litígio decorrente dos clientes podem motivar auditores de alta qualidade a evitar clientes de risco em maior grau do que os auditores de baixa qualidade. Entretanto, auditores de alta qualidade são mais capazes de minimizar o risco de litígio e aumentar a qualidade da auditoria.

Nesse sentido, infere-se que auditores maiores, chamados Big Four, têm maior qualidade e consequentemente maior capacidade de diversificar o risco do cliente do que auditores menores, não Big Four (Elder Zhang, Zhou \& Zhou, 2009; Krishnan, Sun, Wang \& Yang, 2013). Neste contexto, firmas de auditoria Big Four podem achar lucrativo manter clientes, mesmo fornecendo altos riscos de litígios ao auditor. Deste modo, auditores de alta qualidade ou Big Four, podem aceitar clientes com maiores riscos e compensar o risco com honorários elevados.

A responsabilidade do auditor está relacionada com o risco envolvido no processo, portanto, quanto maior o risco do trabalho de auditoria, maior a responsabilidade, fato que demanda honorários de auditoria mais altos para compensar o risco assumido (Kikhia, 2015). O estudo realizado por Sun \& Liu (2011) apontou que o cliente com alto nível de risco forçará os auditores a realizar procedimentos de auditoria de forma eficaz, desse modo, o risco deve ser incorporado no trabalho de auditoria para determinar atividades e esforços a serem realizados. Além disso, uma empresa com maiores riscos identificados exige uma atenção e uma quantidade de testes de auditoria maiores, que pode resultar no aumento dos honorários de auditoria (Simunic, 1980).

Presume-se que cientes do risco de litígio decorrente do cliente, os auditores podem realizar auditorias mais conservadoras e cobrar honorários de auditoria mais altos. Conforme Elder et al. (2009), o aumento do risco de litígio causado pelo cliente ocasiona uma resposta dos auditores, que é refletida por meio do ajuste dos honorários de auditoria, a emissão de opiniões modificadas ou ainda, pode causar a renúncia do auditor.

No que tange à relação entre os temas, risco de litígio do auditor decorrente do cliente e honorários de auditoria, infere-se que empresas com maior risco exigirão mais trabalho e esforços do auditor, o que consequentemente pode aumentar os honorários de auditoria (Simunic \& Stein, 1996). Nesse sentido, honorários de auditoria mais elevados, provavelmente incluem aumentos temporários no trabalho de auditoria (Abbott, Gunny \& Pollard, 2017), que podem ser consequência do risco de litígio do auditor, decorrente do cliente auditado.

Diante do exposto, estabeleceu-se a primeira hipótese do estudo com o intuito de relacionar os honorários de auditoria com o risco de litígio do auditor:

\section{- $\mathrm{H}_{1}$ : As firmas de auditoria cobram honorários de auditoria mais elevados dos clientes que apresentam maior risco de litígio ao auditor.}

Tratando-se dos honorários de não auditoria, o questionamento efetuado pelos reguladores é que a prestação desses serviços dificulta a independência do auditor (Lim \& Tan, 2007). A literatura anterior sobre serviços de não auditoria apresenta que a realização desses serviços cria ligações econômicas que enfraquecem a independência do auditor e consequentemente a qualidade da auditoria (Simunuc, 1984; DeAngelo, 1981). Entretanto, a preocupação com a reputação e a exposição a litígios (Watts e Zimmerman, 1983) pode motivar os auditores a serem mais independentes na realização de seus trabalhos de não auditoria (Lim, Ding e Charoenwong, 2013). Nesse sentido, quanto maior o risco de litígio do auditor, maior será a atenção e o trabalho na realização de serviços de não auditoria, o que pode resultar em maiores honorários de não auditoria.

A independência e qualidade da auditoria realizada pelos auditores não deve ser prejudicada por serviços prestados que não sejam de auditoria, deste modo, é preciso que exista um equilíbrio entre a independência e qualidade da auditoria e o fator econômico decorrente do serviço prestado (Lim\& Tan, 2007). DeFond, Raghunandan \& Subramanyam (2002) relatam que as preocupações dos auditores sobre a perda de reputação e custos de litígio são superiores aos benefícios esperados de comprometer sua independência. 
Dessa forma, os auditores devem manter a independência e preservar a qualidade da auditoria mesmo quando fornecem serviços que não sejam de auditoria, as preocupações com perdas de reputação e exposição a litígios devem ser suficientes para que a prestação de serviços de não auditoria seja de qualidade. Além disso, devido às preocupações de reputação e possível exposição a riscos de litígios, é provável que os auditores forneçam alta qualidade de auditoria quando também prestam serviços que não são de auditoria aos clientes (Lim, Ding \& Charoenwong, 2013).

Hay, Knechel \& Ling (2008) apontam que a demanda por serviços de auditoria é uma função do conjunto de riscos enfrentados pelas partes interessadas em uma organização (credores, gerentes, acionistas, etc.) e um conjunto de mecanismos de controle disponíveis para mitigar esses riscos. Dessa forma, os riscos do cliente de auditoria também apresentam relação com a demanda por honorários de não auditoria, tendo como objetivo a busca pela minimização do risco presente. Portanto, o auditor terá que realizar um trabalho detalhado para atenuar o risco, o que causa um aumento do seu esforço (Kikhia, 2015) e pode resultar no aumento de honorários de não auditoria.

Conforme Antle, Gordon, Narayanamoorthy \& Zhou (2006), os honorários de não auditoria estão relacionados a muitos fatores, como o montante do contas a receber e estoques, desempenho passado e características do cliente (Ashbaugh, LaFond \& Mayhew, 2003; Firth, 1997). Nesse sentido, as características do cliente incluem fatores de risco relacionados a ele, e apresenta-se relacionado com o risco de litígio do auditor, o que pode influenciar nos honorários de não auditoria.

Com base no supracitado, estabeleceu-se a segunda hipótese do estudo com o intuito de testar a influência dos honorários de não auditoria com o risco de litígio do auditor:

- $\mathrm{H}_{2}$ : As firmas de auditoria cobram honorários de não auditoria mais elevados dos clientes que apresentam maior risco de litígio ao auditor.

\section{Procedimentos Metodológicos}

Com um estudo de cunho descrito, documental e de natureza quantitativa, identificou-se uma população de 11.505 companhias abertas, localizadas nos Estados Unidos da América, que continham dados na base Thomson Reuters Eikon ${ }^{\circledR}$. Desta população, para fins de obtenção da amostra, foram excluídas as empresas que não possuíam dados disponíveis das variáveis utilizadas no estudo, resultando em uma amostra final de 1.298 companhias abertas listadas que totalizou 6.490 observações. O período de análise compreendeu os anos de 2013 a 2017. Os dados referentes às variáveis independentes, dependente e de controle estão descritas com base em estudos que as suportam, conforme apresentado na Tabela 1. 
Tabela 1

Variáveis utilizadas no estudo

\begin{tabular}{|c|c|c|c|}
\hline Variável & Descrição & Métrica & Autor(es) \\
\hline \multicolumn{4}{|c|}{ Variáveis Dependentes } \\
\hline HAUD & Honorário de Auditoria & $\begin{array}{l}\text { Logaritmo do valor total pago de } \\
\text { honorários de auditoria. }\end{array}$ & $\begin{array}{l}\text { Kikhia (2015); Jaramillo, Benau } \\
\text { e Grima (2012); Venkataraman, } \\
\text { Weber e Willenborg (2008); Abbott } \\
\text { et al. (2003); Joshi e Hasan (2000). }\end{array}$ \\
\hline HNAUD & Honorário de Não Auditoria & $\begin{array}{l}\text { Logaritmo do valor total pago de } \\
\text { honorários de não auditoria. }\end{array}$ & $\begin{array}{l}\text { Jaramillo, Benau e Grima (2012); } \\
\text { Abbott et al. (2003). }\end{array}$ \\
\hline \multicolumn{4}{|c|}{ Variável Independente } \\
\hline RLIT & Risco de Litígio & Equação 1 & $\begin{array}{c}\text { Sun e Liu (2011); Krishnan e Zhang } \\
\text { (2005); Shu (2000). }\end{array}$ \\
\hline \multicolumn{4}{|c|}{ Variáveis de Controle } \\
\hline ALAV & Alavancagem & & $\begin{array}{c}\text { Venkataraman, Weber e } \\
\text { Willenborg (2008); Abbott et al. } \\
\text { (2003). }\end{array}$ \\
\hline LUCR & Lucratividade & & $\begin{array}{c}\text { Jaramillo, Benau e Grima (2012); } \\
\text { Joshi e Hasan (2000). }\end{array}$ \\
\hline BigN & Empresa de auditoria & $\begin{array}{c}\text { Dummy: } 1 \text { se empresa de } \\
\text { auditoria é Big Four e } 0 \text { caso } \\
\text { contrário. }\end{array}$ & $\begin{array}{c}\text { Kikhia (2015); Jaramillo, Benau } \\
\text { e Grima (2012); Sun e Liu } \\
\text { (2011); Venkataraman, Weber } \\
\text { e Willenborg (2008); Mayoral e } \\
\text { Segura (2007); Carson, et al. (2004). }\end{array}$ \\
\hline
\end{tabular}

Fonte: dados da pesquisa.

A escolha dos possíveis determinantes para explicar o valor dos honorários de auditoria e honorários de não auditoria, no modelo proposto, teve como base as variáveis utilizadas pelas pesquisas prévias. Quanto ao risco de litígio do auditor, tendo em vista que este está associado a muitos fatores (Shu, 2000; Carcello \& Palmrose, 1994; Lys\& Watts, 1994; Stice, 1991), é necessário usar uma medida abrangente de medição. Shu (2000) explica o risco de litígio do auditor usando quatorze características da empresa auditada.

Para mensurar o risco de litígio do auditor utilizou-se a proxy desenvolvida por Shu (2000) também utilizada nos estudos de Sun \& Liu (2011) e Krishnan \& Zhang (2005), conforme apresentada na Equação 1.

$$
\begin{gathered}
R L I T=0,276^{\star} T A M+1,153^{\star} E S T+2,075^{\star} R E C+1,251^{\star} R O A+ \\
1,501^{\star} L G+0,301^{\star} C V-0,371^{\star} R E T+0,235^{\star} M B+1,464^{\star} P A+ \\
1,060^{\star} D I F+0,928^{\star} S E T+0,463^{\star} O P-10,049
\end{gathered}
$$

Em que:

- RLIT: Risco de litígio.

- TAM (Tamanho): logaritmo natural do total de ativos.

- $E S T$ (Estoque): estoque dividido pelo total de ativos.

- $\quad$ REC (Receita): clientes divididos pelo total de ativos.

- ROA (Retorno sobre o Ativo): lucro líquido dividido pelo ativo total.

- $\quad L G$ (Liquidez Geral): total do ativo dividido pelo total do passivo no final do ano.

- $\quad C V$ (Crescimento das Vendas): vendas do ano anterior menos as vendas do ano atual divididas pelas vendas do ano anterior. 
- $\quad$ RET (Retorno das Ações): distribuição de dividendos no último dia do ano fiscal.

- $\quad M B$ (Maketto Book): preço de mercado das ações dividido pelo valor contábil das ações no último dia do exercício fiscal.

- $\quad P A$ (Proporção de Ações): proporção de ações que foram negociadas durante o ano fiscal.

- DIF (Dificuldade Financeira): 1 se a empresa apresentou patrimônio líquido negativo no ano anterior e 0 caso contrário.

- $\quad$ SET (Setor): 1 se a empresa for dos setores código 2830, 3570, 7370, 8730, e entre 3825 e 3839 (segmentos da saúde, tecnologia da informação e telecomunicações) e 0 caso contrário.

- $O P$ (Opinião de Auditoria): 1 se a empresa recebeu uma opinião de auditoria modificada no ano anterior, e 0 caso contrário.

A Equação 2 é utilizada para testar a hipótese $\mathrm{H}_{1}$ e a Equação 3 é utilizada para testar a hipótese $\mathrm{H}_{2}$ do estudo.

$$
\begin{gathered}
\text { HAUD }=\beta_{0}+\beta_{1} \text { RLIT }+\beta_{2} \mathrm{ALAV}+\beta_{3} \mathrm{LUCR}+ \\
\beta_{4} \mathrm{BigN}+\sum \text { efeito_fixo_setor } r_{\mathrm{it}}+\sum \text { efeito_fixo_ano }{ }_{\mathrm{it}}+\boldsymbol{\varepsilon} \\
\mathrm{HNAUD}=\beta_{0}+\beta_{1} \mathrm{RLIT}+\beta_{2} \mathrm{ALAV}+\beta_{3} \mathrm{LUCR}++\beta_{4} \\
\text { BigN }+\beta \text { Eefeito_fixo_setor }{ }_{\mathrm{it}}+\sum e f e i t o \_f i x o \_a n o_{\mathrm{it}}+\boldsymbol{\varepsilon}
\end{gathered}
$$

Para verificar se o risco de litígio do auditor afeta os honorários de auditoria e honorários de não auditoria nas empresas dos Estados Unidos da América, inicialmente, realizou-se o teste de normalidade Shapiro-Wilk, o qual demonstrou que os dados não são normais $(\mathrm{Z}=14,134 ; \mathrm{Z}<0,000)$, entretanto, devido ao tamanho da amostra utilizada, assume-se normalidade pelo Teorema do Limite Central. Posteriormente foi realizada a Correlação de Spearman e, para análise do modelo proposto, operacionalizaram-se as Equações 2 e 3, por meio de regressões Ordinary Least Squares (OLS) com erros padrão robustos e controle de efeito fixo de setor e ano.

Justifica-se a realização de regressão robusta devido ao teste White apresentar-se significativo $(\mathrm{P}=214,07 ; \mathrm{p}<0,000)$, o que indica a presença de heterocedasticidade. Em relação ao controle de efeitos fixos de setor e ano, estes permitem que os resultados não sejam influenciados por características particulares, como, por exemplo, setor e, conforme Mayoral \& Segura (2007), o controle fixo do ano tem como objetivo controlar possíveis efeitos temporários e fatores macroeconômicos. Todos os testes foram realizados no software estatístico STATA $14^{\circledR}$.

\section{Análise dos Resultados}

Esta sessão apresenta a descrição e análise dos achados encontrados no presente estudo. Inicia-se com a apresentação e análise da estatística descritiva das variáveis utilizadas, posteriormente a Correlação de Spearman entre as variáveis e, por fim, as regressões, com o intuito de analisar se há relação entre o risco de litígio e os honorários de auditoria e honorários de não auditoria. A partir da Tabela, 2 apresenta-se a estatística descritiva das variáveis utilizadas na presente pesquisa. 
Tabela 2

\section{Análise descritiva das variáveis}

\begin{tabular}{lrrrr}
\hline \multicolumn{1}{c}{ Variáveis } & \multicolumn{1}{c}{ Mínimo } & \multicolumn{1}{c}{ Máximo } & \multicolumn{1}{c}{ Média } & \multicolumn{1}{c}{ Desvio-Padrão } \\
\hline Honorários de Auditoria* & 7,5 & $485.991,00$ & $3.251,00$ & $13.635,00$ \\
\hline Honorários de Não Auditoria* & 0,00 & $36.400,00$ & 244,00 & $1.225,00$ \\
\hline Risco de Litígio & $-13,203$ & 13,650 & 3,377 & 2,189 \\
\hline Alavancagem & $-2,601$ & 8,561 & 0,352 & 0,350 \\
\hline Lucratividade & 3,903 & 10,512 & 7,799 & 0,851 \\
\hline Empresa de Auditoria & 0 & 1 & 0,781 & 0,413 \\
\hline
\end{tabular}

*Expresso em milhares dólares.

Fonte: dados da pesquisa.

Como observado na Tabela 2, os valores dos honorários de auditoria e de não auditoria das empresas da amostra apresentam valores discrepantes. Destaca-se que para os honorários de não auditoria, algumas empresas não apresentaram gastos com o uso desse serviço. Em relação à variável independente risco de litígio, verifica-se que em média as empresas fornecem um risco de 3,377 aos auditores, entretanto, algumas empresas chegam a um risco de 13,650.

As demais variáveis também apresentaram diferenças consideráveis. A alavancagem e a lucratividade evidenciaram valores discrepantes, as quais podem estar relacionadas ao setor econômico das empresas. Ainda, quanto à empresa de auditoria, observa-se que a maior parte das empresas são auditadas por firmas Big Four, pois a média $(0,781)$ apresentou-se mais próximo de 1.

Na sequência, mensuraram-se a intensidade e o sentido da relação entre as variáveis, por meio do coeficiente de Correlação de Spearman, com o propósito de identificar possíveis problemas de multicolinearidade nos dados. Segundo Fávero (2015), a presença de multicolinearidade não significa problemas do modelo, mas sua presença elevada gera um aumento no erro. Nesse sentido, a correlação não sugere necessariamente uma relação de causa e efeito, mas, sim, de associação entre as variáveis do estudo. Os resultados da Correlação de Spearman são apresentados na Tabela 3.

Tabela 3

\section{Correlação de Spearman entre as variáveis}

\begin{tabular}{|c|c|c|c|c|c|c|}
\hline & HAUD & HNAUD & RLIT & ALAV & LUCR & BigN \\
\hline HAUD & 1 & $1,000 * *$ & $0,766 * *$ & $0,387 * *$ & $0,709 * *$ & $0,540 * *$ \\
\hline HNAUD & & 1 & $0,766^{* *}$ & $0,387 * *$ & $0,709 * \star$ & $0,540 * *$ \\
\hline RLIT & & & 1 & $0,444^{* *}$ & $0,772^{* *}$ & $0,454^{* *}$ \\
\hline ALAV & & & & 1 & $0,364 * \star$ & $0,194 * *$ \\
\hline LUCR & & & & & 1 & $0,438 * *$ \\
\hline BigN & & & & & & 1 \\
\hline
\end{tabular}

**A correlação é significativa no nível 1\%. HAUD= Honorários de auditoria; HNAUD= Honorários de não auditoria; RLIT= Risco de Litígio; ALAV= Alavancagem; LUCR= Lucratividade; BigN= Empresas de auditoria.

Fonte: dados da pesquisa.

Observa-se na Tabela 3 que a matriz de correlação de Spearman das variáveis da pesquisa fornece evidências preliminares de que a variável independente risco de litígio está positivamente relacionada aos honorários de auditoria e de não auditoria. Além disso, verificou-se a existência de relação entre as variáveis dependentes honorários de auditoria e honorários de não auditoria com as demais variáveis de controle, alavancagem, lucratividade e firma de auditoria. 
Referente aos honorários de auditoria, as variáveis risco de litígio $(0,766)$, alavancagem $(0,387)$, lucratividade $(0,709)$ e firma de auditoria $(0,540)$ apresentaram uma correlação significativa e positiva ao nível de $1 \%$. Tratando-se dos honorários de não auditoria, as variáveis risco de litígio $(0,766)$, alavancagem $(0,387)$, lucratividade $(0,709)$ efirma de auditoria $(0,540)$ também apresentaram uma correlação significativa e positiva ao nível de $1 \%$.

No que tange àss variáveis explicativas da pesquisa, observa-se uma alta correlação entre elas. Destaca-se a correlação de $77 \%$ entre o risco de litígio e a lucratividade das empresas analisadas. Além disso, o risco de litígio apresentou forte correlação com a alavancagem e as firmas de auditoria, sendo de $44 \%$ e $45 \%$, respectivamente. Ademais, a alavancagem apresentou uma correlação de $36 \%$ com a lucratividade e a lucratividade uma correlação de aproximadamente $44 \%$ com a variável empresa de auditoria (BigN).

Em relação a esses achados, presume-se que os honorários de auditoria e de não auditoria estão associados positivamente com o risco de litígio nas empresas analisadas. Destaca-se, entretanto, que a Correlação de Spearman apresenta apenas a associação existente entre as variáveis. Dessa forma, para a realização do teste das hipóteses da influência do risco de litígio e demais variáveis de controle nos honorários de auditoria e de não auditoria, realizou-se a regressão OLS cujos resultados estão apresentados na Tabela 4.

Tabela 4

Resultados do modelo da Regressão Linear Múltipla

\begin{tabular}{|c|c|c|c|}
\hline \multicolumn{2}{|c|}{ Variável } & $\begin{array}{l}\text { Honorários de Auditoria } \\
\text { (Equação 2) }\end{array}$ & $\begin{array}{l}\text { Honorários de Não Auditoria } \\
\text { (Equação 3) }\end{array}$ \\
\hline \multirow{2}{*}{ Constante } & Coeficiente & 3,834 & 0,448 \\
\hline & Sig. & $0,000 * * *$ & $0,000 * \star \star$ \\
\hline \multirow{2}{*}{ Risco de Litígio } & Coeficiente & 0,085 & 0,006 \\
\hline & Sig. & $0,000 * * \star$ & $0,000 * \star \star$ \\
\hline \multirow{2}{*}{ Alavancagem } & Coeficiente & $-0,021$ & $-0,001$ \\
\hline & Sig. & 0,192 & 0,143 \\
\hline \multirow{2}{*}{ Lucratividade } & Coeficiente & 0,228 & 0,015 \\
\hline & Sig. & $0,000 * * *$ & $0,000 * * *$ \\
\hline \multirow{2}{*}{$\begin{array}{l}\text { Empresa de } \\
\text { Auditoria }\end{array}$} & Coeficiente & 0,275 & 0,021 \\
\hline & Sig. & $0,000 * * *$ & $0,000 * * *$ \\
\hline \multicolumn{2}{|c|}{ Efeitos Fixos Setor e Ano } & Sim & Sim \\
\hline \multicolumn{2}{|l|}{ Sig. do modelo } & $0,000 * * *$ & $0,000 * * *$ \\
\hline \multicolumn{2}{|l|}{$\mathrm{R}^{2}$} & 65,11 & 65,90 \\
\hline \multicolumn{2}{|l|}{$\mathrm{R}^{2}$ Ajustado } & 65,02 & 65,81 \\
\hline \multicolumn{2}{|l|}{ Durbin-Watson } & 2,058 & 2,048 \\
\hline \multicolumn{2}{|l|}{ VIF } & $1,16-2,20$ & $1,16-2,20$ \\
\hline \multicolumn{2}{|c|}{ Número de observações } & 6.490 & 6,490 \\
\hline
\end{tabular}

***significância a nível de 1\%; **5\%; *10\%. Regressão OLS com erros padrão robustos e controle de efeito fixo de setor e ano. VIF=Variancelnflator Factor; Sig.=significância.

Fonte: dados da pesquisa. 
Conforme verificado na Tabela 4, os modelos demonstraram significância de 1\%. O teste VIF de multicolinearidade entre as variáveis apresentou valores abaixo de 10 para os dois modelos, o que demonstra a aceitabilidade dos dados quanto a este pressuposto. O teste Durbin-Watson também demonstrou aceitabilidade dos dados quanto ao pressuposto de autocorrelação serial nos resíduos, por apresentar valores próximos a 2 .

O poder de explicação dos modelos econométricos, observado por meio do $\mathrm{R}^{2}$, em relação aos honorários de auditoria, foi de $65,11 \%$, e tratando-se dos honorários de não auditoria, o poder explicativo foi de $65,90 \%$. Em relação ao $\mathrm{R}^{2}$ ajustado, o qual indica uma noção de quanto o modelo generaliza os resultados, em que quanto mais próximo do valor do $\mathrm{R}^{2}$ maior será o poder de explicação do modelo, pode-se observar que o $\mathrm{R}^{2}$ ajustado dos honorários de auditoria é de $65,02 \%$ e dos honorários de não auditoria $65,81 \%$, demonstrando que o poder de explicação dos modelos são significativos.

Estudos anteriores, sobre determinantes de honorários de auditoria e honorários de não auditoria, apresentaram modelos com poder explicativos $\left(\mathrm{R}^{2}\right)$ que variavam entre $17,4 \%$ e $80,1 \%$ (Kikhia, 2015; Jaramillo, Benau \& Grima, 2012; Venkataraman, Weber \& Willenborg, 2008; Abbott et al., 2003; Joshi \& Hasan, 2000). Nesse sentido, de acordo com os estudos evidenciados na literatura, observa-se que ambos os modelos do presente estudo demonstram um poder de explicação robusto, pois, quando comparados com outras pesquisas, os modelos apresentam-se entre os de maior poder explicativo.

Em relação à Equação 2, no que tange à variável independente, nota-se, conforme a Tabela 4, que o risco de litígio se apresentou significativo e positivo em relação aos honorários de auditoria. Este resultado indica que o risco de litígio impacta nos honorários de auditoria, ou seja, quanto maior (menor) o risco de litígio, maior (menor) será o valor cobrado referente aos honorários de auditoria. Em termos econômicos, o coeficiente de 0,085 (Tabela 4) indica que a variação de um desvio padrão no risco de litígio representa uma alteração em torno de $18 \%\left(0,085^{\star} 2,189\right.$ (Tabela 2)) nos honorários de auditoria.

Diante da evidência encontrada para essa variável no modelo, aceita-se a hipótese $\mathrm{H}_{1}$ de que as firmas de auditoria cobram honorários de auditoria mais elevados de clientes que apresentam maior risco de litígio ao auditor. Este resultado corrobora com o estudo de Venkataraman, Weber e Willenborg (2008) o qual relatou que a exposição do auditor ao risco de litígio reflete nos honorários de auditoria.

Esse achado indica que a partir da identificação de um alto risco de litígio, os auditores são instigados a despender um maior esforço e tempo no trabalho de auditoria, como, por exemplo, por meio do aumento da aplicação de testes (Bronson, Ghosh \& Hogan, 2017; Simunic \& Stein, 1996), fato que pode levar a firma de auditoria a cobrar um prêmio pelo trabalho e risco assumido (Bronson, Ghosh \& Hogan, 2017). Entretanto, não é possível identificar a quantidade de horas despendidas pelo auditor em decorrência do aumento do trabalho (DeFond \& Zhang, 2014) devido a um alto risco de litígio. Esse fato apresenta-se como uma limitação, pois salienta-se que o montante pago à firma de auditoria não especifica o valor pago por um esforço adicional decorrente do risco de litígio.

Os resultados da Equação 3 evidenciaram que o risco de litígio apresentou uma relação significativa e positiva com os honorários de não auditoria. Esse resultado sugere que quanto maior (menor) o risco de litígio, maior (menor) será o valor cobrado pelos honorários de não auditoria. Em relação à análise econômica, o coeficiente de 0,006 (Tabela 4) indica que a variação de um desvio padrão no risco de litígio representa um aumento de 1,3\% $\left(0,006^{\star} 2,189\right.$ (Tabela 2)) nos honorários de não auditoria. Esse achado suporta a hipótese $\mathrm{H}_{2}$ de que as firmas de auditoria cobram honorários de não auditoria mais elevados de clientes que apresentam maior risco de litígio ao auditor. Nesse contexto, Sun \& Liu (2011), mencionam que perante um alto risco de litígio, os auditores são motivados a despender mais esforços e realizar um trabalho especializado, como, por exemplo, auditoria com demanda especial e verificação fiscal.

Referente às demais variáveis explicativas (de controle), a alavancagem não apresentou relação significativa nos dois modelos. Apesar de não constatar uma relação significativa, fato que diverge do estudo realizado por Abbott et al. (2003), os quais evidenciaram uma relação negativa e significativa da alavancagem em ambos os honorários, observa-se que o sinal negativo é condizente com o estudo dos autores. 
A variável lucratividade mostrou-se significativa e positiva em relação aos honorários de auditoria e honorários de não auditoria. Esses resultados sugerem que empresas lucrativas pagam mais honorários de auditoria e de não auditoria, tendo em vista que lucros maiores podem exigir testes rigorosos de auditoria em testes de controle e substantivos, o que também requer mais tempo de auditoria. Esse achado reforça o estudo de Joshi \& Hasan (2000), o qual evidenciou esse resultado ao analisar a relação entre lucratividade e honorários de auditoria e honorários de não auditoria. Em contraponto a esse resultado, o estudo de Jaramillo, Benau \& Grima (2012) não confirmou a lucratividade como fator que influência os honorários, essa divergência pode estar relacionada ao país no qual o estudo foi realizado, sendo que os autores analisaram o mercado mexicano, com uma amostra de 59 empresas.

Em relação à variável firma de auditoria, observou-se uma associação significativa e positiva tanto com os honorários de auditoria como os de não auditoria. Nesse sentido, entende-se que grandes firmas de auditoria possuem maior incentivo para proteger sua reputação e assim oferecem serviços de alta qualidade (Sun \& Liu, 2011), o que implicam honorários de auditoria e de não auditoria mais elevados. Tal resultado corrobora com os estudos de Kikhia (2015), Jaramillo, Benau \& Grima (2012), Venkataraman, Weber \& Willenborg (2008), Mayoral \& Segura (2007) e Carson, et al. (2004), os quais demonstraram que os honorários são mais elevados quando as empresas são auditadas por uma firma de auditoria Big Four.

De forma geral, o presente estudo evidenciou que o risco de litígio do auditor, decorrente de características do cliente, corresponde a um dos fatores considerados para estabelecer o valor dos honorários do auditor. Conforme Sun \& Liu (2011), um maior risco de litígio do auditor demanda uma maior supervisão e especialização por parte desse profissional, sendo que este empenho em prestar o serviço é sustentado por valores mais altos de honorários de auditoria e honorários de não auditoria. Além disso, outros fatores já evidenciados na literatura foram reforçados por meio deste estudo, como determinantes dos honorários de auditoria e honorários de não auditoria, os quais correspondem à alavancagem, à lucratividade e à empresa de auditoria.

Por fim, a aplicação empírica do modelo de mensuração de risco de litígio desenvolvido por Shu (2000), no contexto norte-americano, possibilitou verificar o risco de litígio do auditor, o qual está associado a características do cliente, além de inferir a influência do mesmo nos honorários de auditoria e de não auditoria. Destaca-se o número de observações do estudo e o poder explicativo do modelo testado, os quais forneceram robustez aos resultados, quando comparados a outros estudos que buscaram evidenciar os determinantes dos honorários de auditoria. Ainda, observa-se que o cenário norte-americano é um mercado financeiro forte e desenvolvido, desta forma, os achados deste estudo podem ser utilizados como parâmetro para empresas e firmas de auditoria em outros ambientes do mercado, quando for tratado sobre honorários de auditoria, não auditoria e risco de litígio do auditor.

\section{Conclusão}

O estudo objetivou analisar a influência do risco de litígio do auditor nos honorários de auditoria e de não auditoria nas empresas listadas nos Estados Unidos da América. A pesquisa foi caracterizada como descritiva, quantitativa e documental com o período de análise dos dados dos anos de 2013 a 2017.

Duas hipóteses foram testadas em relação ao objetivo proposto. A primeira corresponde às firmas de auditoria que cobram honorários de auditoria mais elevados dos clientes que apresentam maior risco de litígio ao auditor. Embora tal relação possa parecer evidente, nenhum estudo ainda efetuou tal verificação ao segregar empresas que apresentam possibilidades de litígio e de não litígio. Para tanto, utilizou-se o modelo de risco de litígio desenvolvido por Shu (2000), o qual foi elaborado com dados do mercado norteamericano. Com esta identificação foi possível, então, verificar a influência do risco de litígio, além de outras variáveis de controle, nos honorários de auditoria. O resultado encontrado demonstra a existência de relação significativa e positiva, estatisticamente ao nível de $1 \%$. 
$\mathrm{Na}$ prática, este resultado indica que a partir do momento em que o auditor percebe um alto risco de litígio da empresa auditada, este é inclinado a despender um maior esforço e tempo na aplicação de testes para realizar o trabalho de auditoria (Bronson, Ghosh \& Hogan, 2017; Simunic \& Stein, 1996). Sendo que esse fato pode implicar no aumento do valor cobrado de honorários de auditoria, devido ao trabalho e risco assumido pelo auditor. Além da variável risco de litígio, as variáveis de controle, lucratividade e empresa de auditoria também apresentaram relação, contribuindo na identificação de fatores explicativos do montante dos honorários de auditoria.

A hipótese 2 refere-se às firmas de auditoria que cobram honorários de não auditoria mais elevados dos clientes que apresentam maior risco de litígio ao auditor. Da mesma forma que se observou com os honorários de auditoria, o risco de litígio do auditor também apresentou relação significativa e positiva estatisticamente ao nível de $1 \%$ com os honorários de não auditoria.

Nesse sentido, infere-se que, perante um alto risco de litígio, os auditores são motivados a despender mais esforços e realizar um trabalho especializado, como, por exemplo, auditoria especial, verificação fiscal, fusões e aquisições (Sun \& Liu, 2011). Dessa forma, a realização de um maior número de atividades, consequentemente, influencia no aumento dos valores referente a honorários de não auditoria. Ainda, as variáveis de controle lucratividade e empresa de auditoria também apresentaram-se significativas ao nível de $1 \%$ em relação aos honorários de não auditoria.

Este estudo contribui para a literatura ao fornecer evidências sobre o teste da relação entre o risco de litígio do auditor e os honorários de auditoria e honorários de não auditoria. Ademais, enfoca o risco de litígios do auditor, mensurado por meio de características do cliente. Adicionalmente, os resultados do estudo também contribuem ao evidenciar o reflexo econômico do risco de litígio do auditor nos honorários de auditoria e de não auditoria, sendo de $18 \%$ e 1,3\%, respectivamente.

As limitações do estudo consistem no modelo de risco de litígio utilizado, sendo este específico para mensuração no cenário norte-americano, o que impossibilita a generalização dos resultados. Pesquisas futuras podem analisar se a relação entre os honorários de auditoria e de não auditoria e o risco de litígio do auditor é diferente entre empresas de capital aberto e fechado. Ainda, estudos futuros podem verificar outros períodos e também outros mercados acionários, como, por exemplo, países em desenvolvimento. Sugere-se que estudos futuros também avaliem diferenças econômicas, culturais do sistema jurídico e fatores macroeconômicos em diferentes países em relação ao risco de litígio do auditor e aos honorários de auditoria e de não auditoria.

\section{Referências}

Abbott, L. J., Gunny, K., \& Pollard, T. (2017). The Impact of Litigation Risk on Auditor Pricing Behavior: Evidence From Reverse Mergers. Contemporary Accounting Research, 34(2), pp. 1103-1127. Doi: https://doi.org/10.1111/1911-3846.12300

Abbott, L. J., Parker, S., Peters, G. F., \&Raghunandan, K. (2003). An empirical investigation of audit fees, nonaudit fees, and audit committees. Contemporary Accounting Research, 20(2), pp. 215-234.Doi: https://doi.org/10.1506/8YP9-P27G-5NW5-DJKK

Antle, R., Gordon, E., Narayanamoorthy, G., \& Zhou, L. (2006). The joint determination of audit fees, non-audit fees, and abnormal accruals. Review of Quantitative Finance and Accounting, 27(3), pp. 235-266. Doi: https://doi.org/10.1007/s11156-006-9430-y

Ashbaugh, H., LaFond, R., \& Mayhew, B. W. (2003). Do nonaudit services compromise auditor independence? Further evidence. The accounting review, 78(3), pp. 611-639. Doi: https://doi. org/10.2308/accr.2003.78.3.611 
Badertscher, B., Jorgensen, B., Katz, S., \& Kinney, W. (2014). Public equity and audit pricing in the United States. Journal of Accounting Research, 52(2), pp. 303-339. Doi: https://doi.org/10.1111/1475679X.12041 Recuperado de: https://www.jstor.org/stable/24518212

Bronson, S. N., Ghosh, A. A., \& Hogan, C. E. (2017). Audit Fee Differential, Audit Effort, and Litigation Risk: An Examination of ADR Firms. Contemporary Accounting Research, 34(1), pp. 83-117.Doi: https://doi.org/10.1111/1911-3846.12238

Carcello, J. V., \&Palmrose, Z. V. (1994). Auditor litigation and modified reporting on bankrupt clients. Journal of Accounting Research, 32, pp. 1-30. Doi: 10.2307/2491436 https://www.jstor.org/ stable/2491436

Carson, E., Fargher, N., Simon, D. T., \& Taylor, M. H. (2004). Audit fees and market segmentation-further evidence on how client size matters within the context of audit fee models. International Journal of Auditing, 8(1), pp. 79-91.Doi: https://doi.org/10.1111/j.1099-1123.2004.00159.x

Cahan, S. F., \& Zhang, W. (2006). After Enron: Auditor conservatism and ex-Andersen clients. The Accounting Review, 81(1), pp. 49-82.Doi: https://doi.org/10.2308/accr.2006.81.1.49

Choi, J. H., Kim, J. B., Liu, X., \&Simunic, D. A. (2009). Cross-listing audit fee premiums: Theory and evidence. The Accounting Review, 84(5), pp. 1429-1463.Doi: https://doi.org/10.2308/ accr.2009.84.5.1429

DeAngelo, L. E. (1981). Auditor size and audit quality. Journal of accounting and economics, 3(3), pp. 183199.Doi: https://doi.org/10.1016/0165-4101(81)90002-1

DeFond, M. L., Raghunandan, K., \& Subramanyam, K. R. (2002). Do non-audit service fees impair auditor independence? Evidence from going concern audit opinions. Journal of accounting research, 40(4), pp.1247-1274. Doi: https://www.jstor.org/stable/3542312

DeFond, M., \& Zhang, J. (2014). A review of archival auditing research. Journal of Accounting and Economics, 58(2-3), pp. 275-326.Doi: https://doi.org/10.1016/j.jacceco.2014.09.002

Elder, R., Zhang, Y., Zhou, J., \& Zhou, N. (2009). Internal control weaknesses and client risk management. Journal of Accounting, Auditing \& Finance, 24(4), pp. 543-579. Doi: https://doi. org/10.1177/0148558X0902400403

Fávero, L. P. (2015). Análise de Dados: Modelos de Regressão com Excel ${ }^{\circledR}$, STATA $^{\oplus}$ e SPSS ${ }^{\bullet}$ (1a ed). Rio de Janeiro: Elsevier.

Firth, M. (1997). The provision of nonaudit services by accounting firms to their audit clients. Contemporary Accounting Research, 14(2), pp. 1-21. Doi: https://doi.org/10.1111/j.1911-3846.1997.tb00524.x

Ghosh, A., \& Tang, C. Y. (2015). Auditor resignation and risk factors. Accounting Horizons, 29(3), pp. 529549.Doi: https://doi.org/10.2308/acch-51074

Hay, D., Knechel, W. R., \& Ling, H. (2008). Evidence on the impact of internal control and corporate governance on audit fees. International Journal of Auditing, 12(1), pp. 9-24.Doi: https://doi. org/10.1111/j.1099-1123.2008.00367.x

Hay, D. C., Knechel, W. R., \& Wong, N. (2006). Audit fees: A meta-analysis of the effect of supply and demand attributes. Contemporary accounting research, 23(1), pp. 141-191.Doi: https://doi. org/10.1506/4XR4-KT5V-E8CN-91GX

Heninger, W. G. (2001). The association between auditor litigation and abnormal accruals. The Accounting Review, 76(1), pp. 111-126.Doi: https://doi.org/10.2308/accr.2001.76.1.111

Hoitash, R., Markelevich, A., \&Barragato, C. A. (2007). Auditor fees and audit quality. Managerial Auditing Journal, 22(8), pp. 761-786.Doi: https://doi.org/10.1108/02686900710819634 
Hope, O. K., \&Langli, J. C. (2010). Auditor independence in a private firm and low litigation risk setting. The Accounting Review, 85(2), pp. 573-605.Doi: https://doi.org/10.2308/accr.2010.85.2.573

Jaramillo, M. J., Benau, M. A. G., \&Grima, A. Z. (2012). Factores que determinanloshonorarios de auditoría: Análisis empírico para México. Revista Venezolana de Gerencia, 17(59), pp. 387-406. Recuperado em <https://www.redalyc.org/pdf/290/29024166002.pdf>

Joshi, P. L., \&Bastaki, H. A. (2000). Determinants of audit fees: evidence from the companies listed in Bahrain. International journal of auditing, 4(2), pp. 129-138. Doi: https://doi.org/10.1111/10991123.00308

Kaplan, S. E., \& Williams, D. D. (2013). Do going concern audit reports protect auditors from litigation? A simultaneous equations approach. The Accounting Review, 88(1), pp. 199-232.Doi: https://doi. org/10.2308/accr-50279

Kikhia, H. Y. (2015). Determinants of audit fees: evidence from Jordan. Accounting and finance Research, 4(1), pp. 42-53.Doi: https://doi.org/10.5430/afr.v4n1p42

Kim, Y., \& Park, M. S. (2013). Real activities manipulation and auditors' client-retention decisions. The Accounting Review, 89(1), pp. 367-401.Doi: https://doi.org/10.2308/accr-50586

Krishnan, J., \& Krishnan, J. (1997). Litigation risk and auditor resignations. Accounting Review, pp. 539560.Recuperado em < https://www.jstor.org/stable/248174>

Krishnan, J., \& Zhang, Y. (2005). Auditor litigation risk and corporate disclosure of quarterly review report. Auditing: A Journal of Practice \& Theory, 24(s-1), pp. 115-138. Doi: https://doi.org/10.2308/ aud.2005.24.s-1.115

Krishnan, G. V., Sun, L., Wang, Q., \& Yang, R. (2013). Client risk management: A pecking order analysis of auditor response to upward earnings management risk. Auditing: A Journal of Practice \& Theory, 32(2), pp. 147-169.Doi: https://doi.org/10.2308/ajpt-50372

Lim, C. Y., Ding, D. K., \&Charoenwong, C. (2013). Non-audit fees, institutional monitoring, and audit quality. Review of Quantitative Finance and Accounting, 41(2), pp. 343-384. Doi: https://doi. org/10.1007/s11156-012-0312-1

Lim, C. Y., \& Tan, H. T. (2008). Non-audit service fees and audit quality: The impact of auditor specialization. Journal of accounting research, 46(1), pp. 199-246. Doi: https://doi.org/10.1111/ j.1475-679X.2007.00266.x

Lys, T., \& Watts, R. L. (1994). Lawsuits against auditors. Journal of accounting research, 32, pp. 65-93. Doi: https://doi.org/10.2307/2491440https://www.jstor.org/stable/2491440

Mayoral, J. A. M., \& Segura, A. S. (2007). um estudio empírico de los honorários del auditor. Cuadernos de Economía y Dirección de la Empresa, (32), pp. 81-110.Doi: https://doi.org/10.1016/S11385758(07)70092-0

Schmidt, J. J. (2012). Perceived auditor independence and audit litigation: The role of nonaudit services fees. The Accounting Review, 87(3), pp. 1033-1065. Doi: https://doi.org/10.2308/accr-10217

Seetharaman, A., Gul, F. A., \& Lynn, S. G. (2002). Litigation risk and audit fees: Evidence from UK firms cross-listed on US markets. Journal of accounting and economics, 33(1), pp. 91-115. Doi: https://doi. org/10.1016/S0165-4101(01)00046-5

Simunic, D. A. (1984). Auditing, consulting, and auditor independence. Journal of Accounting research, 22(2), pp. 679-702.Doi: https://doi.org/10.2307/2490671https://www.jstor.org/stable/2490671

Simunic, D. A. (1980). The pricing of audit services: Theory and evidence. Journal of accounting research, 18(1), pp. 161-190. Doi: https://doi.org/10.2307/2490397https://www.jstor.org/stable/2490397 
Simunic, D., \& M. Stein. (1996). The Impact of Litigation Risk on Audit Pricing: A Review of the Economics and the Evidence. Auditing: A Journal of Practice \& Theory Vol. 15, pp. 119-34. Recuperado em: <https://search.proquest.com/docview/216733305?pq-origsite=gscholar\&from openview=true $>$

Shu, S. Z. (2000), Auditor resignations: clientele effects and legal liability, Journal of Accounting and Economics, Vol. 29(2), pp. 173-205. Doi: https://doi.org/10.1016/S0165-4101(00)00019-7

Sterzeck, G. (2017). Audit Expectation Gap nos litígios das firmas de auditoria (Doctoral dissertation, Universidade de São Paulo). Doi: 10.11606/T.12.2017.tde-14062017-093241

Stice, J. D. (1991). Using financial and market information to identify pre-engagement factors associated with lawsuits against auditors. Accounting Review, 66(3), pp.516-533. Recuperado em< https://www. jstor.org/stable/247807>

Sun, J., \& Liu, G. (2011). Client-specific litigation risk and audit quality differentiation. Managerial Auditing Journal, 26(4), pp. 300-316. Doi: https://doi.org/10.1108/02686901111124639

Venkataraman, R., Weber, J. P., \&Willenborg, M. (2008). Litigation risk, audit quality, and audit fees: Evidence from initial public offerings. The Accounting Review, 83(5), pp. 1315-1345. Doi: https:// doi.org/10.2308/accr.2008.83.5.1315

Watts, R. L., \& Zimmerman, J. L. (1983). Agency problems, auditing, and the theory of the firm: Some evidence. The Journal of Law and Economics, 26(3), pp. 613-633.Doi: https://www.journals.uchicago. edu/doi/abs/10.1086/467051?journalCode=jle

Whisenant, S., Sankaraguruswamy, S., \&Raghunandan, K. (2003). Evidence on the joint determination of audit and non-audit fees. Journal of accounting research, 41(4), pp. 721-744. Doi: https://doi. org/10.1111/1475-679X.00121

Zaman, M., Hudaib, M., \&Haniffa, R. (2011). Corporate governance quality, audit fees and non-audit services fees. Journalof Business Finance\&Accounting, 38(1-2), pp. 165-197. Doi: https://doi. $\operatorname{org} / 10.1111 /$ j.1468-5957.2010.02224.x 